\title{
Hidatidosis multiorgánica con compromiso peritoneal. Reporte de un caso y revisión de la literatura
}

\author{
Dres. Nelson Montaña $C^{(1)}$, Fernando Chávez $T^{(2)}$.
}

1. Residente de Radiología Universidad Mayor. Santiago - Chile.

2. Médico Radiólogo, Hospital Barros Luco Trudeau. Santiago - Chile.

\section{Multi-organ hydatidosis with peritoneal involvement. A case report and literature review.}

\begin{abstract}
Hydatidosis is a parasitic disease whose etiologic agent is the tapeworm of the genus Echinococcus, the species most frequently involved being E. granulosus and E. multilocularis. It can affect any organ, but most often is associated with liver and lung involvement. The classic imaging findings in organs that are usually involved are fully described, but not so for those in unusual locations. We report a case of multi-organ hydatidosis with peritoneal and pericardial commitment, studied with ultrasound and computed tomography, with a review of the currently available literature regarding this.
\end{abstract}

Keywords: Encysted peritoneal hydatidosis, Multi-organ hydatidosis, Peritoneal dissemination, Peritoneal hydatidosis, Peritoneal seeding.

Resumen: La hidatidosis es una parasitosis cuyo agente etiológico es el céstodo del género Echinococcus, siendo las especies más frecuentemente involucradas la E. granulosus y E. multilocularis. Puede afectar a cualquier órgano, aunque con mayor frecuencia se asocia a compromiso hepático y pulmonar. Los hallazgos imagenológicos clásicos en órganos habitualmente comprometidos están ampliamente descritos, no así en localizaciones poco comunes. Presentamos un caso de hidatidosis multiorgánica con compromiso peritoneal y pericárdico, estudiado con ultrasonido y tomografía computada, con revisión de la literatura actualmente disponible al respecto.

Palabras clave: Diseminación peritoneal, Hidatidosis multiorgánica, Hidatidosis peritoneal, Siembra peritoneal.

Montaña $N$, et al. Hidatidosis multiorgánica con compromiso peritoneal. Reporte de un caso y revisión de la literatura. Rev Chil Radiol 2014; 20(1): 26-30.

Correspondencia: Nelson Montaña C. / montana.nela@gmail.com.

Trabajo recibido el 13 de mayo de 2013. Aceptado para publicación el 03 de marzo de 2014.

\section{Introducción}

La hidatidosis es una parasitosis causada más frecuentemente por el estado larval del cestodo $\mathrm{E}$. granulosus. Está distribuida en todo el mundo y puede afectar cualquier órgano del cuerpo siendo lo más frecuente el compromiso hepático y pulmonar. Los hallazgos más comunes de las localizaciones frecuentes están ampliamente detallados en la literatura, no así el compromiso en lugares inusuales. Dentro de estos últimos se encuentra la hidatidosis peritoneal, correspondiendo a un $13 \%$ de hidatidosis abdominales. A continuación se expone un caso de hidatidosis multiorgánica asociado a hidatidosis peritoneal enquistada junto a los hallazgos ultrasonográficos y por tomografía computada, además de revisión de la literatura actualmente disponible al respecto.

\section{Caso Clínico}

Paciente de sexo masculino, 43 años, oriundo de la Región del Biobío (Chile), con antecedente de quistectomía pulmonar en la base izquierda 20 años antes de la consulta actual. Acude a control médico por cuadro de dos meses de evolución, caracterizados por compromiso del estado general, baja de peso, constipación e intolerancia progresiva a la alimentación oral. Al examen físico, destacan masas palpables a nivel del epigastrio, flanco derecho y hemiabdomen inferior. Se solicita ultrasonido (US) abdominal como primer estudio, el cual revela innumerables lesiones quísticas de distinto tamaños, algunas tabicadas, con contenido ecogénico que se movilizan con los cambios de posición del paciente, ocupando toda la cavidad intraperitoneal. Dichas lesiones comprome- 
ten además el hígado y el bazo (Figura 1). Se indica hospitalización para estudio y manejo, solicitándose serología ELISA IgG para E. granulosus, la cual resultó positiva, y tomografía computada (TC) de tórax, abdomen y pelvis que objetiva compromiso pericárdico, hepático, esplénico, pancreático, del tubo digestivo y peritoneal por el mismo tipo de lesiones visualizadas previamente con ultrasonido. Dichas lesiones se asocian además a una moderada hidroureteronefrosis que impresiona secundaria a compresión extrínseca ejercida por parte de las masas quísticas (Figuras 2 y 3). Dados los antecedentes clínicos y epidemiológicos, examen de laboratorio, además de los hallazgos imagenológicos, se realiza el diagnóstico de hidatidosis intrabdominal con com- promiso multiorgánico, peritoneal y pericárdico. Se indica tratamiento farmacológico con Albendazol y controles imagenológicos mensuales con tomografía computada de abdomen y pelvis con contraste, para evaluar eventual intervención quirúrgica. Al cuarto mes de tratamiento, se observa que las lesiones han presentado una evolución heterogénea: mientras el compromiso pericárdico ha regresado por completo, a nivel abdominal hay evidencia de regresión parcial, estabilidad y progresión de la enfermedad en distintos órganos. Debido a esto, se decide no realizar cirugía, dado los riesgos que ésta conlleva, indicándose ciclos de Albendazol con controles imagenológicos, que se instaurarán según sintomatología del paciente, dándose de alta con control ambulatorio.

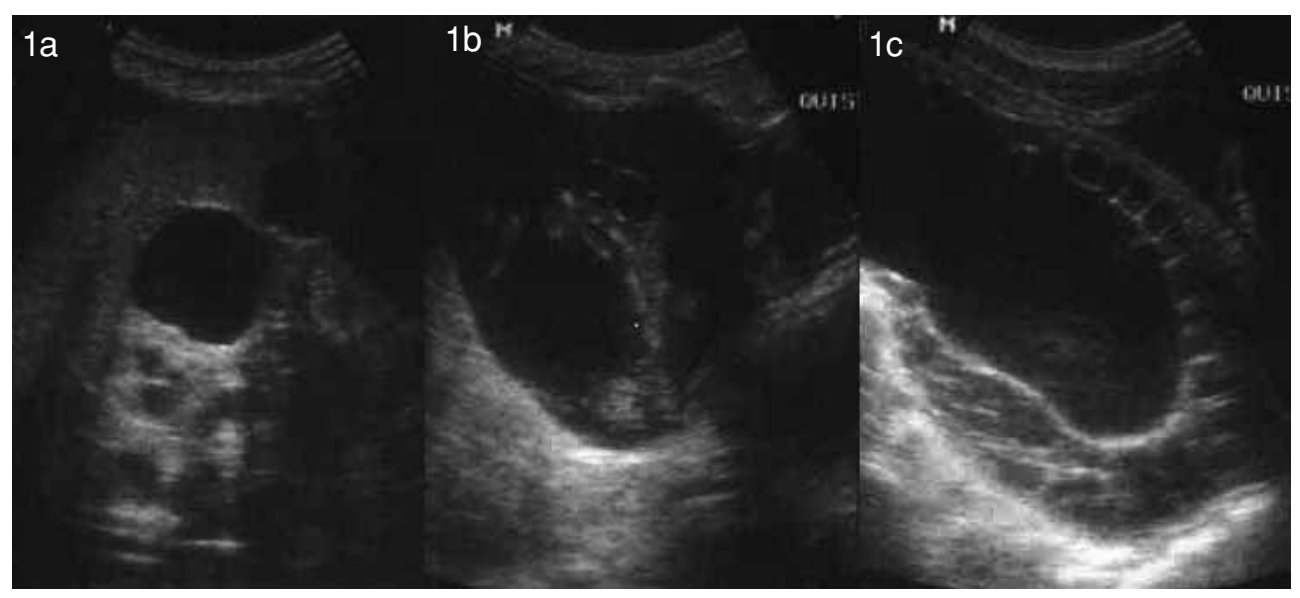

Figura 1. Ecotomografía abdominal, imágenes del lóbulo hepático derecho (a), del bazo (b) y fondo de saco recto-vesical (c). Se observan en las tres imágenes múltiples quistes, loculados en la figura b y c. No se logró una adecuada visualización del resto de los órganos intraperitoneales como retroperitoneales. El contenido ecogénico visible en el interior de algunos quistes se modificaba con los cambios de posición.

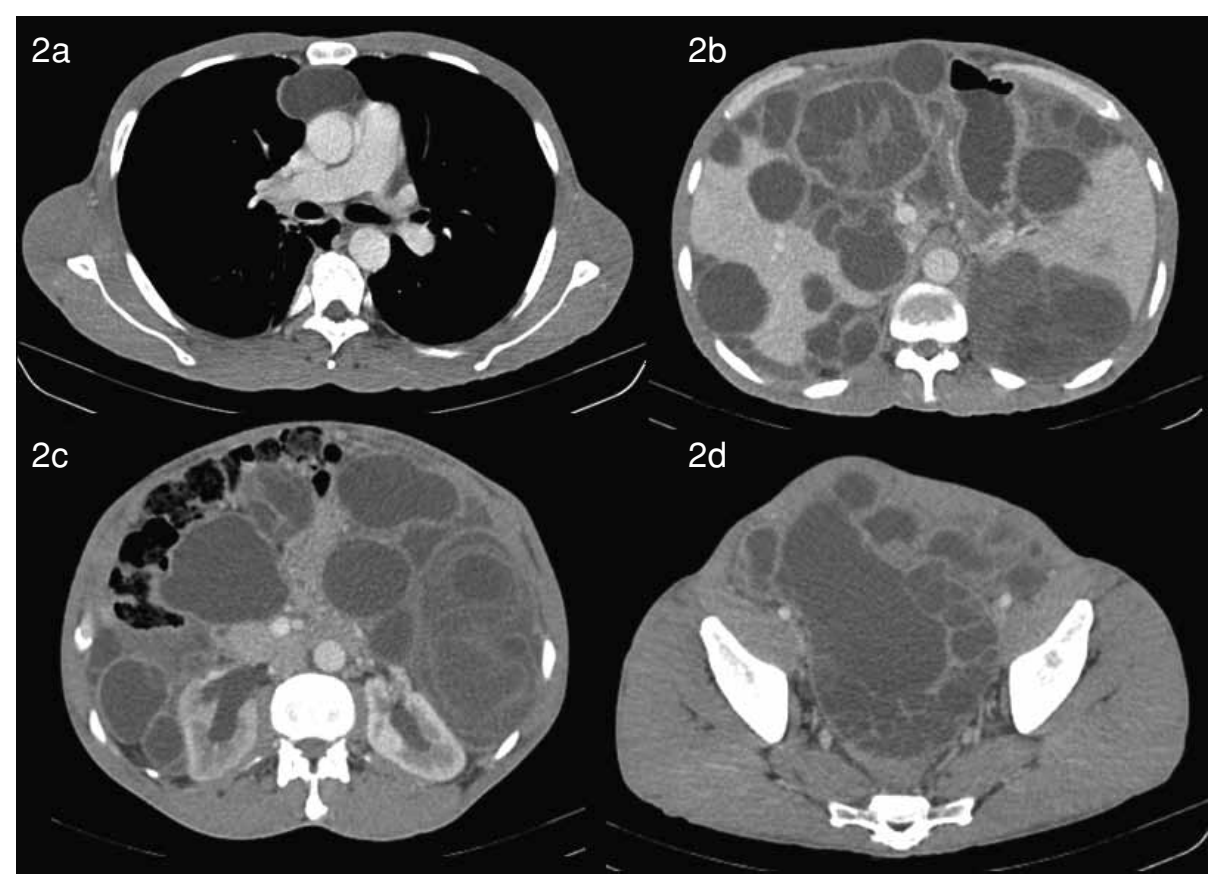

Figura 2. Cortes axiales de tomografía computada de tórax abdomen y pelvis con el uso de medio de contraste intravenoso a nivel cardíaco (a), supramesocólico (b), renal (c) y cavidad pelviana (d). Se observa compromiso pericárdico, hepático, esplénico y peritoneal. No se observan lesiones focales a nivel renal, pero sí efecto masa sobre éstos por los múltiples quistes, además de hidroureteronefrosis, probablemente secundario a efecto compresivo extrínseco por la gran lesión a nivel del saco recto-vesical, también observable en las imágenes de la ecografía. Dicha lesión desplazaba a la vejiga anteriormente. No había compromiso pulmonar u óseo. 


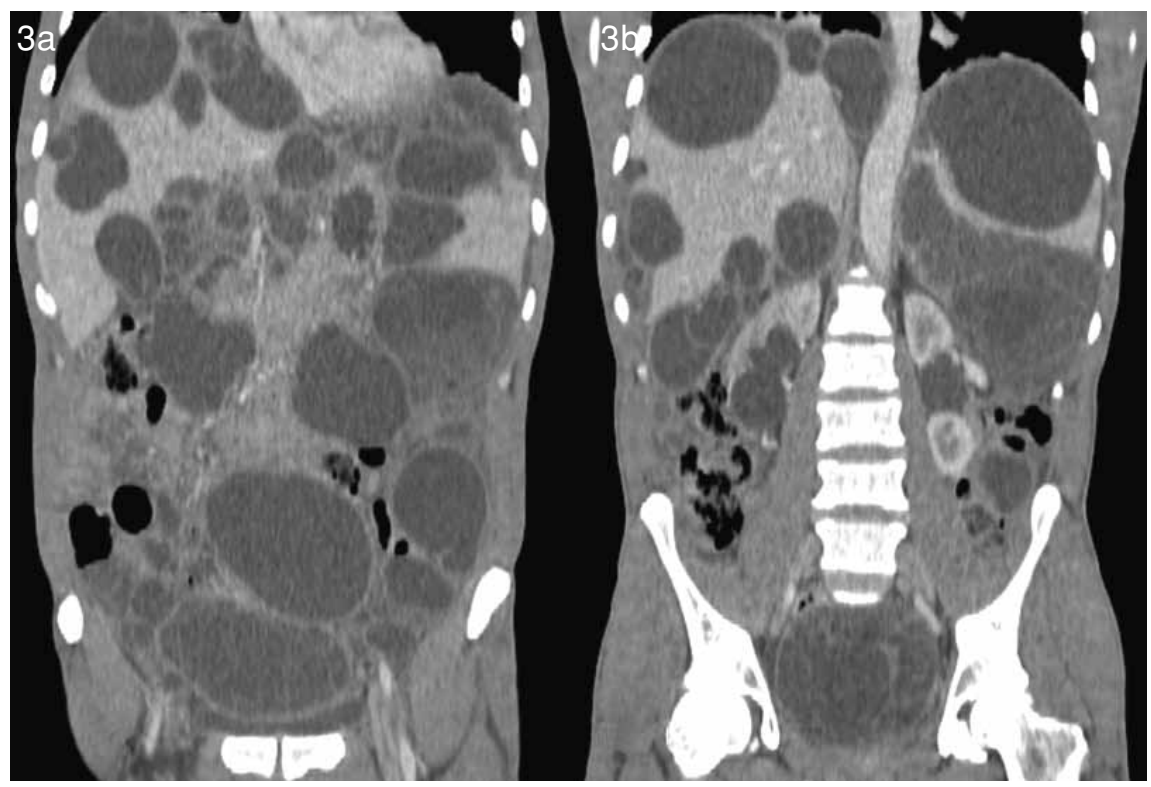

Figura 3. Cortes coronales de tomografía computada con el uso de medio de contraste intravenoso a nivel de la sínfisis púbica y pre-sacral. Se logra una mejor localización de las lesiones que da una mejor idea del grado de compromiso de este paciente.

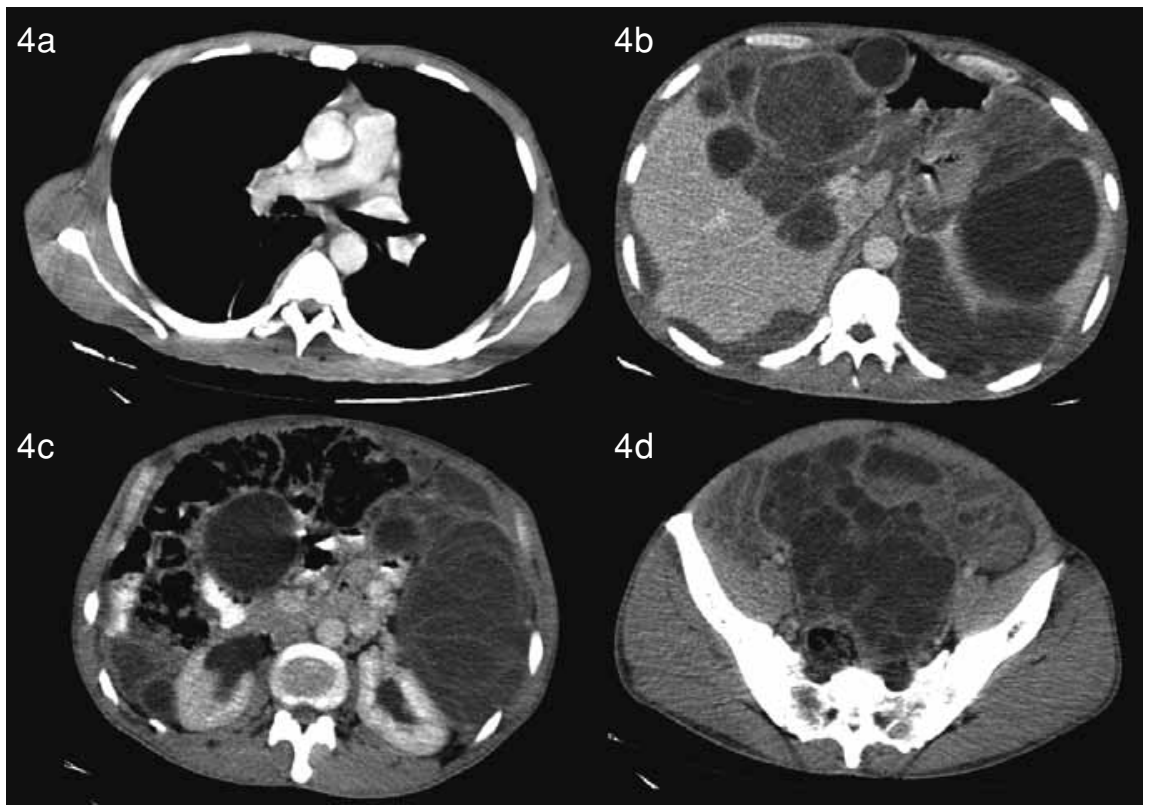

Figura 4. Cortes axiales de tomografía computada de tórax abdomen y pelvis con el uso de medio de contraste intravenoso, luego de 4 meses de tratamiento médico con Albendazol. Se muestran cortes axiales similares a los exhibidos en la figura 2 a nivel cardíaco (a), supramesocólico (b), renal (c) y cavidad pelviana (d). En este control se observa una respuesta mixta al tratamiento, ya que se aprecia regresión completa del compromiso pericárdico, regresión parcial del compromiso hepático principalmente en su aspecto posterior, estabilidad del compromiso peritoneal, aumento del compromiso esplénico y mayor número de las vesículas hijas a nivel pelviano. Ambos riñones se mantienen aparentemente indemnes.

\section{Discusión}

La hidatidosis es una parasitosis causada por el estado larval de cestodos de la familia de Echinococcus, siendo las especies más frecuentemente involucradas E. granulosus y E. multilocularis. Representan un problema endémico en algunos lugares del mundo como Sudáfrica, Medio-Oriente, el Mar Mediterráneo, África y Australia, mientras que en otros lugares, como Europa, es una afección poco frecuente y más bien propia de inmigrantes o personas que viajaron a zonas endémicas ${ }^{(1,2)}$.

En orden de frecuencia las presentaciones clínicas incluyen el compromiso hepático (55-70\%), pulmonar (18-35\%), hepato-pulmonar (5-13\%), esplénico (5\%) y otros lugares $(5 \%)^{(3-5)}$. Estos últimos incluyen el compromiso peritoneal, renal, suprarrenal, ovárico, pancreático, tiroideo, pleural, diafragmático, uterino y cerebral ${ }^{(3,5)}$.
Los hallazgos radiológicos clásicos en los órganos más frecuentemente comprometidos están ampliamente descritos, sin embargo las características en relación a localizaciones poco usuales se encuentran poco desarrolladas en la literatura ${ }^{(1,2)}$.

La enfermedad peritoneal es una entidad poco común, con una frecuencia establecida del $13 \%$ de las hidatidosis abdominales ${ }^{(1,2,5,6)}$. Existen las formas primarias y secundarias, siendo estas últimas las más frecuentes, definidas por la presencia de enfermedad en el peritoneo y el antecedente o concomitancia de afectación en otro lugar ${ }^{(1-3)}$. La mayoría de los casos se relacionan a cirugía practicada por hidatidosis hepática, ocurriendo por rotura espontánea asintomática en un $12 \%{ }^{(1,6)}$. La rotura de estos quistes resulta en la diseminación de vesículas hijas y de los escólex, que se implantan en el peritoneo para luego desarrollarse independientemente, dando paso a una hidatidosis 
secundaria intraperitoneal. Estos implantes pueden crecer y ocupar toda la cavidad peritoneal, simulando una masa multilobulada, entidad conocida como hidatidosis peritoneal enquistada (en inglés, encysted peritoneal hidatidosis) $)^{(1,5,7,8)}$.

La hidatidosis peritoneal, por lo general, se desarrolla de manera asintomática, causando molestias sólo cuando los quistes son lo suficientemente grandes para comprometer y/o comprimir los órganos intra-abdominales ${ }^{(1)}$.

Frecuentemente se solicita como primer estudio imagenológico, por costo y disponibilidad, una ecotomografía abdominal, identificándose múltiples lesiones quísticas con o sin tabiques y/o lóculos. La tomografía computada es el estudio de elección, ya que permite examinar el abdomen en toda su extensión así como también la pelvis. Una tomografía con doble contraste presenta un 90 a 100\% de precisión para el diagnóstico de esta patología ${ }^{(2,5,9)}$, sin embargo, también se describe el uso de resonancia magnética(5).

Imagenológicamente se observan múltiples lesiones de carácter quístico, que comprometen tanto la cavidad peritoneal como los órganos intra- abdominales en distintos estados evolutivos (Tabla I). El diagnóstico es relativamente sencillo cuando existe el contexto clínico adecuado y se observan quistes con diferentes morfologías, dificultándose cuando las lesiones son de Tipo I o bien son únicas, aunque dichos casos son más bien infrecuentes ${ }^{(1,2)}$.

El tratamiento de esta enfermedad busca mejorar la sintomatología del paciente debido al crecimiento de estos quistes y prevenir sus complicaciones. El manejo consiste en una combinación de una intervención quirúrgica, que busque remover la mayoría de los quistes intra-abdominales, asociado a un período de farmacoterapia con albendazol por un mes y/o prazicuantel por dos semanas, antes y después de la cirugía, reportándose buena respuesta en algunos casos $^{(10-12)}$. En caso de que la cirugía no sea realizable, se realizan ciclos de farmacoterapia a intervalos regulares, reportándose retraso de su progreso (50$70 \%$ ), estabilidad de su curso (20-30\%) y cura de la enfermedad $(10-30 \%)^{(5,12)}$. Se realiza seguimiento imagenológico con ultrasonografía y/o tomografía computada ${ }^{(5)}$. Recomendamos esta última por las razones previamente descritas.

Tabla I. Clasificación imagenológica de quistes hidatídicos ${ }^{(2)}$.

\section{Tipo Características}

* Quiste unilocular

* Contenido homogéneo

* Sedimento al ultrasonido, varía con los cambios de posición

* Halo hipointenso en secuencia T2.

* Quiste multilocular

* Contenido heterogéneo

* Sedimento al ultrasonido, varía con los cambios de posición

* Halo hipotenso en secuencia T2

III * Quiste uni o multicular

* Contenido homogéneo o heterogéneo

* Calcificación completa de su pared asociado o no a calcificación de sus tabiques.

IV * Quiste complicado uni o multilocular

* Rotura: discontinuidad de pared, membranas ondulantes internas, contenido con presencia de aire.

* Sobreinfección: Contenido marcadamente heterogéneo.

* Bordes poco delimitables

* Nivel aire-líquido o líquido-líquido

\section{Comentarios}

* Hidátide sin vesículas hijas

* Sin rotura u otra complicación

* Puede mantenerse en este estado por varios años.

* Hidátide viva sin visículas hijas.

* Sin rotura u otra complicación

* Se subclasifican en lla (vesículas hijas sólo en la periferia del contenido) Illb (vesículas hijas en todo su contenido) y Illc (calcificación parcial de tabiques y/o paredes) que reflejan una mayor longevidad.

* Descrito clásicamente como una hidátide muerta

* Quiste que presenta alguna complicación. Principalmente rotura de sus paredes o sobreinfección del mismo 


\section{Bibliografía}

1. Pedrosa I, Saíz A, Arrazola J, Ferreirós J. Pedrosa CS. Hydatid disease: radiologic and pathologic features and complications. RadioGraphics 2000; 20: 795-817.

2. Polat P, Kantarci M, Alper F, Selami S, Koruyucu MB, Okur A. Hydatid disease from head to Toe.RadioGraphics 2003; 23: 475-494.

3. Iqbal SA, Jawaid M, Usmani F. Disseminated IntraAbdominal Hydatidosis: A Very Rare Presentation. The Internet Journal of Surgery 2007; 11(1): 9.

4. Safioleas MC, Misiakos EP, Kouvaraki M, et al. Hydatid. Disease of the Liver: a continuing surgical problem. Arch Surg 2006; 141: 1101-1108.

5. Raina S, Mahesh DM, Sood V, Mokta JK, Raina R, Kaushal SS. Giant intra-abdominal hydatid cysts with multivisceral locations. Online J Health Allied Scs 2008; 7(2): 10.

6. Karavias DD, Vagianos CE, Kakkos SK, et al. Peritoneal echinococcosis. World J Surg 1996; 20: 337-340.

7. Sahu SK, Singh $P$, Sachan PK, et al. Secondary echinococcosis. Indian J Surg 2006; 68: 334-335.

8. Kathan DL, Griffith-Richards SC, Przybojewski SJ, Strachan M, Vadachia Y, von Bezing H. Encysted peritoneal hydatidosis with a hepatic hydatic cyst. South African Journal of Radiology 2006; 10(3): 3940.

9. Yuksel M, Demirpolat G, Sever A, et al. Hydatid disease involving some rarelocations in the body: a pictorial essay. Korean J Radiol 2007; 8: 531-540.

10. Shah NJ, Vithalani NK, Chaudhary K, Mohite PN. Disseminated peritoneal hydatidosis following blunt abdominal trauma: A case report. Cases Journal 2008; 1 : 118.

11. Primary Peritoneal Hydatidosis: Clinically mimicking carcinoma of ovary. http://www.ispub.com/journal/ the-internet-journal-of-gynecology-and-obstetrics/ volume-7-number-2/primary-peritoneal-hydatidosisclinically-mimicking-carcinoma-of-ovary.html\#sthash. oGjNVR60.dpbs [Último acceso el 28/Nov/2012].

12. Karmali S, Thompson SK, McKinnon G, et al. A 37-year-old woman with fever and abdominal pain 2005; 172: 1683. 